\title{
The effect of composite reducing agent on the reduction process and the tail gas of carbon-containing pellets
}

\author{
Bo Wang ${ }^{1}$, Xueyong Ding ${ }^{1 *}$, Xiaofei Zhang ${ }^{1}$, Tianhua $\mathrm{Ju}^{1}$ and Shigang $\mathrm{Li}^{2}$ \\ ${ }^{1}$ Northeastern University, School of Metallurgy, 110819, Shenyang, China \\ ${ }^{2}$ Beijing Peking University Pioneer Technology Co., Ltd, 100080, Beijing, China
}

\begin{abstract}
In order to explore a reasonable way for the efficient utilization of coal resources in the ironmaking process. In this paper, lignite and bituminous coal are used as reducing agents, and two types of vanadiumtitanium magnetite composite reducing agent pellets are prepared for different content ratios and mixed forms of the two coal powders. Under the simulated rotary kiln pre-reduction conditions, the influence of the ratio and mixing of pulverized coal on the metallization rate and tail gas composition of the reduction process was explored. The results show that increasing the proportion of high volatile lignite is beneficial to the reduction of pellets and can obtain pellets with a higher metallization rate. Under the new pre-reduction process conditions of the rotary kiln, the vanadium-titanium magnetite double-layer pellet with $75 \mathrm{wt} \%$ lignite inside and $25 \mathrm{wt} \%$ bituminous coal outside has the highest metallization rate of about $76 \%$. At the same time, this new type of composite reducing agent pellets reduced gas emissions. This pellet is of great significance to the coal-based ironmaking process.
\end{abstract}

\section{Introduction}

Ironmaking and steelmaking processes generate large amounts of greenhouse gases and consume huge amounts of energy. The $\mathrm{CO}_{2}$ emissions produced by steel mills account for approximately $27 \%$ of the total emissions of the global manufacturing companies[1]. As the global warming situation becomes more severe, exploring advanced technologies to reduce carbon dioxide emissions and save energy is of great significance[2].

Non-blast furnace metallurgy has been greatly developed in recent decades by its advantage of not using metallurgical coke and sinter[3]. In natural gas-rich areas, gas-based ironmaking processes have been developed, such as the COREX process that has been successfully commercialized[4]. In some areas where coal resources are abundant but natural gas is scarce, some coal-based ironmaking processes have also emerged[5, 6]. Four years ago, the Central Iron and Steel Research Institute put forward the pre-reduction in rotary kiln and total oxygen melting pool process, aiming to efficiently and clean use of vanadium-titanium magnetite(VTM)[7-9].

As a typical complex iron ore with the coexistence of titanium and vanadium, VTM is widely distributed in China, especially in the Panxi area[10, 11]. Carboncontaining pellet technology is a low-carbon technology that can reduce energy consumption in the ironmaking process, which has attracted much attention[12-14]. Metallurgical practitioners have investigated the possibility of the effective use of different types of coal reductants in carbon-iron oxide composites and found that increasing biomass-coal can increase the porosity of the pellets and improve the mass transfer conditions $[15,16]$. However, not all regions have abundant sources of biomass charcoal. Therefore, it is still of great significance to develop new structural pellets to improve the utilization of coal resources in existing processes.

Based on the characteristics of the coal-based ironmaking process and carbon-containing pellet technology, we proposed a method of mixing high-quality lignite and ordinary bituminous coal to prepare a new type of vanadium-titanium magnetite carbon-containing pellets. By combining the data from the gas analyzer and the chemical composition analysis of the pellets, the best preparation scheme of the novel pellets is given. This research provides a new approach for the comprehensive utilization of coal and at the same time provides a reference for the development of coal-based technology.

\section{Materials and Methods}

\subsection{Raw Materials}

The experiments used the VTM concentrate powder came from the Panzhihua area, and its chemical composition analysis and phase analysis are shown in Table 1 and Figure 1, respectively. According to Table 1, the Panzhihua VTM belongs to a typical low-iron and hightitanium vanadium-titanium magnetite. Figure 1 indicates that the main crystalline phases of VTM are magnetite $\left(\mathrm{Fe}_{3} \mathrm{O}_{4}\right)$, ilmenite $\left(\mathrm{FeTiO}_{3}\right.$ or $\left.\mathrm{FeO} \cdot \mathrm{TiO}_{2}\right)$, and titanomagnetite $\left(\mathrm{Fe}_{2.75} \mathrm{Ti}_{0.25} \mathrm{O}_{4}\right.$ or $\left.3\left(\mathrm{Fe}_{3} \mathrm{O}_{4}\right) \cdot \mathrm{Fe}_{2} \mathrm{TiO}_{4}\right)$. The

Corresponding author: xyding@mail.neu.edu.cn 
reducing agents were provided by a factory in Liaoning province, and the industry analysis and elemental analysis are shown in Table 2. It can be seen from Table 2 that the volatile content of lignite is much higher than bituminous coal, reaching $35 \%$. While the ash content of bituminous coal is much higher than that of lignite. The fixed carbon and moisture content of these two kinds of coal are very close.

Table 1. The chemical compositions of vanadium-titanium magnetite concentrate (\%).

\begin{tabular}{llllllll}
\hline $\mathrm{TFe}$ & $\mathrm{FeO}$ & $\mathrm{TiO}_{2}$ & $\mathrm{MgO}$ & $\mathrm{SiO}_{2}$ & $\mathrm{Al}_{2} \mathrm{O}_{3}$ & $\mathrm{CaO}$ & $\mathrm{V}_{2} \mathrm{O}_{5}$ \\
\hline 55.55 & 29.31 & 10.27 & 2.28 & 4.88 & 4.11 & 1.47 & 0.62 \\
\hline
\end{tabular}

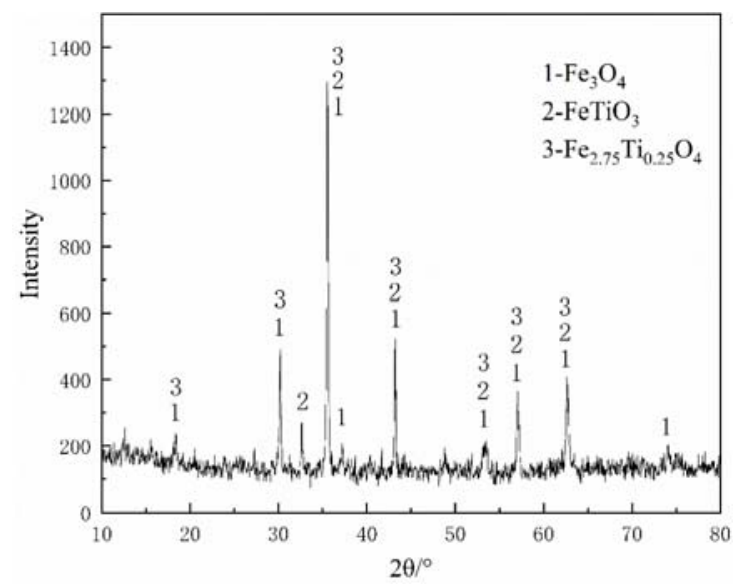

Figure 1. X-ray diffraction pattern of vanadium-titanium magnetite concentrate.

Table 2. Proximate and ultimate analysis of coals (\%).

\begin{tabular}{ccccc}
\hline Species & $\begin{array}{c}\text { Fixed } \\
\text { carbon }\end{array}$ & Volatile & Ash & Moisture \\
\hline Lignite & 56.08 & 35.16 & 4.82 & 3.94 \\
Bituminous coal & 62.91 & 15.73 & 18.49 & 2.87 \\
\hline
\end{tabular}

\subsection{Experimental Equipment and Methods}

Firstly, the vanadium-titanium magnetite and reducing agents were ground to below $0.075 \mathrm{~mm}$ by a mill. Then, add VTM powder, coal powder, molasses and water in different proportions and mix them evenly. Finally, the carbon-containing pellets were prepared by a disc pelletizer. The specific ratio and method are shown in Table 3. The amount of pulverized coal is calculated based on the molar ratio of carbon to oxygen equal to 1 . Table 3 shows the addition ratio of the two types of pulverized coal to the total. In addition, every $100 \mathrm{~g}$ of vanadium-titanium magnetite need $2.5 \mathrm{~g}$ of molasses and $8 \%$ of water as a binder.

Table 3. Pellet preparation scheme.

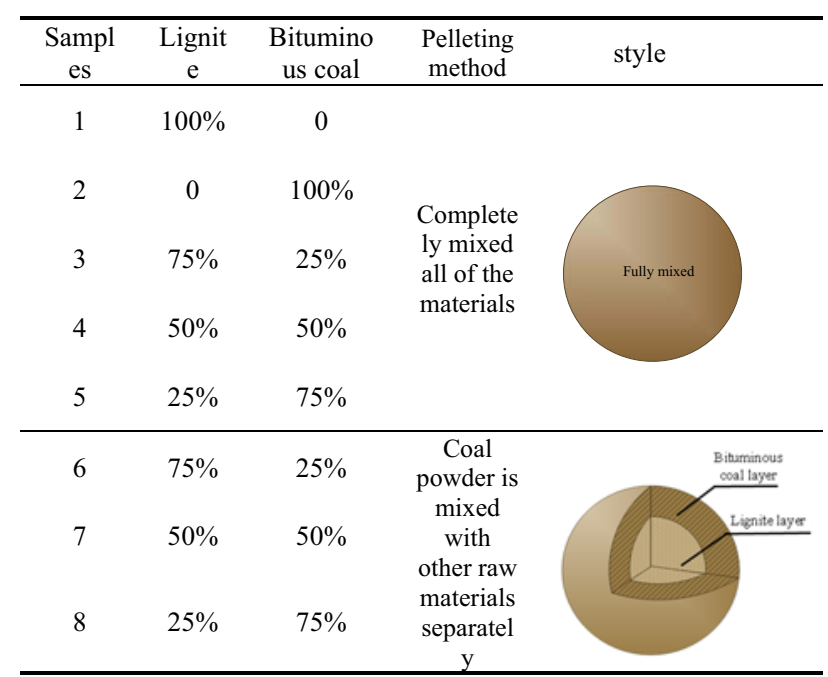

The prepared pellets were dried in an oven at $105{ }^{\circ} \mathrm{C}$ for 5 hours, and then $100 \mathrm{~g}$ pellets were taken out for reduction experiments. The experimental setup is shown in Figure 2. Nitrogen gas was passed through the experiment at a flow rate of $1 \mathrm{~L} / \mathrm{min}$. The heating time was $120 \mathrm{~min}$ and the holding time and reduction temperature were $60 \mathrm{~min}$ and $1000{ }^{\circ} \mathrm{C}$, separately. After the end of the reduction, when the pellets were cooled down to the ambient temperature, take out the samples for testing. In the experimental process, the composition of the gas produced by the pellets was analyzed by the gas analyzer.

The utilization rate of $\mathrm{CO}$ is often used to judge the quality of energy utilization. The calculation formula is as shown in formula (1):

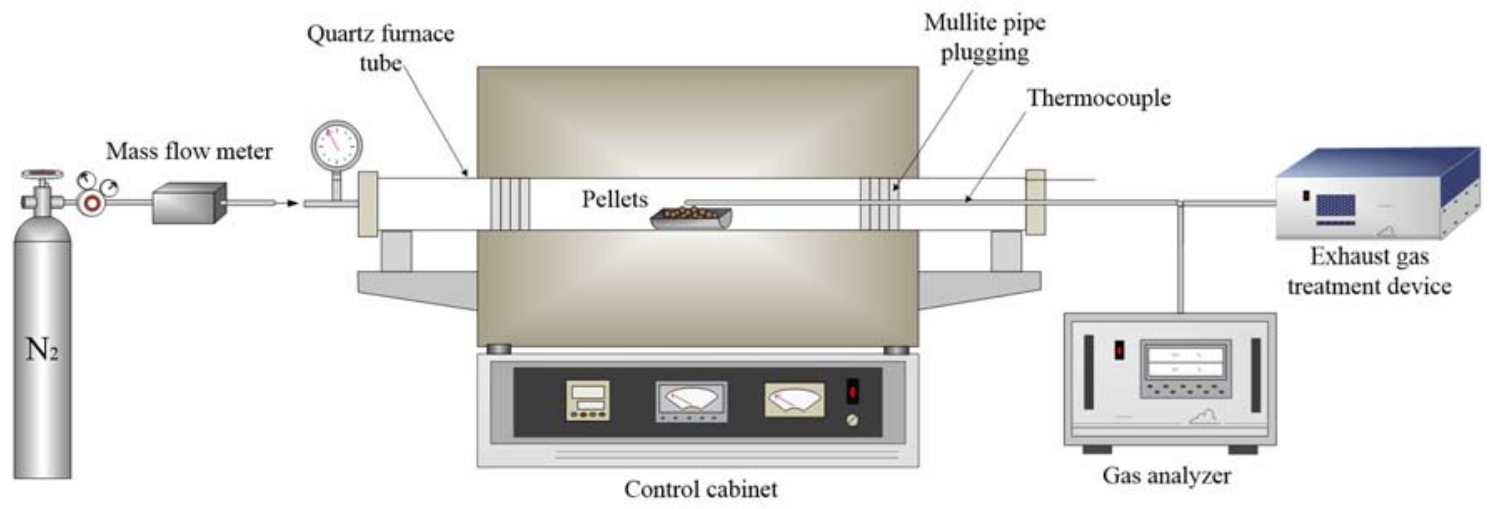

Figure 2. Experimental device and experimental schematic diagram. 


$$
\eta \mathrm{CO}=\frac{\varphi \mathrm{CO}_{2}}{\varphi \mathrm{CO}_{2}+\varphi \mathrm{CO}}
$$

where $\eta \mathrm{CO}$ is the $\mathrm{CO}$ utilization, $\varphi \mathrm{CO}$ and $\varphi \mathrm{CO}_{2}$ respectively represent the volume of $\mathrm{CO}$ and $\mathrm{CO}_{2}$ in the tail gas.

The metallization rate of the pellet after the reaction was defined as the ratio of the content of metallic iron to the content of total iron in the pellet, which can be calculated as follows:

$$
\mathrm{M}=\frac{\omega(\mathrm{MFe})}{\omega(\mathrm{TFe})} \times 100 \%
$$

where $\mathrm{M}_{\text {is }}$ the metallization rate, $\mathrm{MFe}_{\text {and }} \mathrm{TFe}$ are the metallic iron content and total iron content in the reduced pellets, respectively.

\section{Results and Discussion}

\subsection{Metallization rate of different types of pellets}

Figure 3 shows the metallization rate of the different pellets. It can be seen that the metallization rates of pellets prepared by separate coal powder were $75.9 \%$ and $66.4 \%$, respectively. This shows that the reduction effect of high volatile lignite is better than bituminous coal. By observing samples 3,4 , and 5 or samples 6,7 , and 8 , it can be seen that the pellets with a larger amount of lignite added have a higher metallization rate. By comparing samples 4 and 7 or 5 and 8 , it can be seen that the metallization rates of the double-layer pellets and the fully mixed pellets are the same. However, the metallization rate of sample 3 and sample 6 are significantly different. In addition, sample 6 has the highest metallization rate, which is slightly higher than that of sample 1 and much higher than that of sample 2 , reaching $76.2 \%$. This shows that the pelletizing method of sample 6 is more conducive to the reduction of vanadium-titanium ore. In sharp contrast, sample 5 and sample 8 have metallization rates far lower than other pellets, and even lower than singlelayer bituminous coal pellets. This indicates that only a reasonable ratio of the two coal powders can promote the reduction of vanadium-titanium ore, and an improper ratio may even hinder the reduction. Under the experimental conditions, the best pelletizing method is $75 \%$ lignite inside and $25 \%$ bituminous coal outside.

\subsection{Tail gas composition of different types of pellets}

To further analyze the reason for the difference between the metallization rate of the various types of pellets, the tail gas composition of the pellets during the reduction process was analyzed.

Figure 4 shows the tail gas composition of different pellets. Here we can be seen from the figure that sample 1 pellet release the most volume of gas, and sample 2

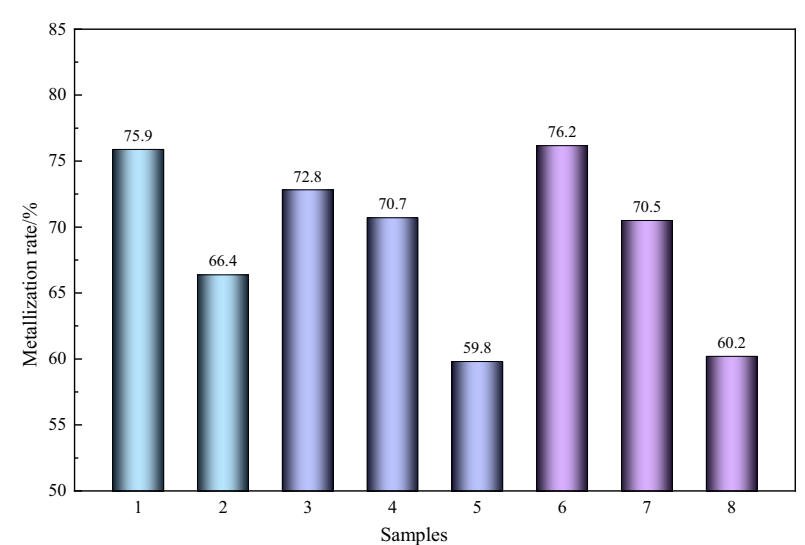

Figure 3. Metallization rate of different pellets.

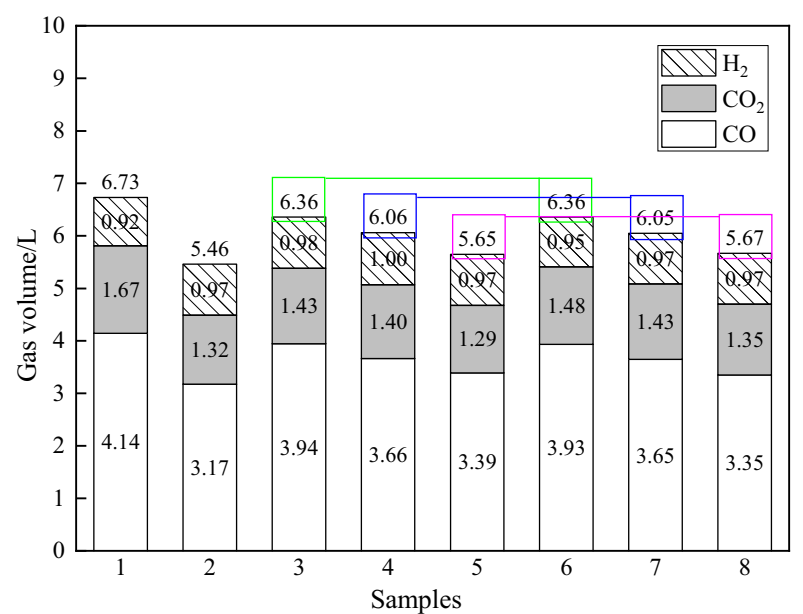

Figure 4. The tail gas composition of different types of pellets.

pellet release the least volume of gas. Which indicate that lignite pellets have strong reducibility, and produces more gas during the reduction process. On the one hand, lignite pellets contain a large amount of volatile matter, with the precipitation of volatile matter the porosity inside the pellets was increased. And the increased porosity will improve the heat and mass transfer conditions of the pellets, which promote the reduction reaction of iron ore and generate more $\mathrm{CO}$ and $\mathrm{CO}_{2}$ gas. On the other hand, the porous structure of lignite pellets promotes the release of the gas inside the pellets, making the tail gas volume more than other pellet samples. Besides, it can be seen from Figure 4 that for pellets with the same pulverized coal ratio, the total volume of tail gas is almost equal. This is consistent with the law of the metallization rate of pellets in Figure 3. It is must be noted that, though the total gas volume of sample 3 and sample 6 are the same, their specific composition is different. In the tail gas of sample 6 , there is less $\mathrm{CO}$, more $\mathrm{CO}_{2}$, and less $\mathrm{H}_{2}$ than sample 3 . Which indicate that in sample 6 , more $\mathrm{CO}$ and $\mathrm{H}_{2}$ participates in the reduction reaction to form $\mathrm{CO}_{2}$ and water vapour. The gas analyzer can only analyze dry gas, so there is no moisture content data.

\subsection{Change trend of $\mathrm{CO}$ and $\mathrm{CO}_{2}$ volume fractions in the tail gas during the reduction process}

Figures 5 and 6 are the volume fractions change curves of 
$\mathrm{CO}, \mathrm{CO}_{2}$ in the pellet reduction process respectively. It can be seen from Figure 5 and Figure 6 that during the heating stage, the $\mathrm{CO}$ and $\mathrm{CO}_{2}$ volume fractions of all pellets gradually increased. When the reduction time was close to $120 \mathrm{~min}$, the $\mathrm{CO}$ volume fractions in the tail gas of pellets with different coal blending ratios began to show differences. First of all, the No. 5 pellet with the lowest addition of lignite showed the $\mathrm{CO}$ peak firstly, followed by the No. 4 pellet with $50 \%$ lignite, and finally the No. 3 pellet with $75 \%$ lignite. As the reduction experiment progressed, the $\mathrm{CO}$ volume fraction began to show a downward trend. The higher the $\mathrm{CO}$ peak, the more $\mathrm{CO}$ gas is produced during the reduction process, which is beneficial to the reduction of vanadium-titanium magnetite.

At the same time, comparing Figure 5 and Figure 6, it can be seen that the $\mathrm{CO}$ and $\mathrm{CO}_{2}$ volume fraction change trends of these two types of pellets are the same. It means the two methods of pelletizing have little impact on the reduction process of pellets. However, as can be seen from the partially enlarged views in Figures 5 and 6, within the same time, the amplitude of the downward trend of the peak value of No. 6 pellet is slightly smaller than that of
No. 3 pellet, This shows that the double-layer pelletizing method can maintain the $\mathrm{CO}$ volume fraction in a higher range than the full-mixed pelletizing method. This can still play a certain strengthening effect on the reduction process of vanadium-titanium magnetite. In addition, it should be pointed out that the double-layer structure allows the bituminous coal with high ash content to form a stronger outer shell, which can effectively reduce the pulverization rate in the reduction process and increase the compressive strength of the pellets. What is more, this structure may improve the oxidation resistance of the pellets, while we are currently researching.

\section{Conclusions}

1. The type of reducing agent, addition ratio and addition method will affect the metallization rate of the pellets. Under simulated rotary kiln process conditions, the vanadium-titanium magnetite double-layer pellet with $75 \mathrm{wt} \%$ lignite inside and $25 \mathrm{wt} \%$ bituminous coal outside has the highest metallization rate about $76.2 \%$.

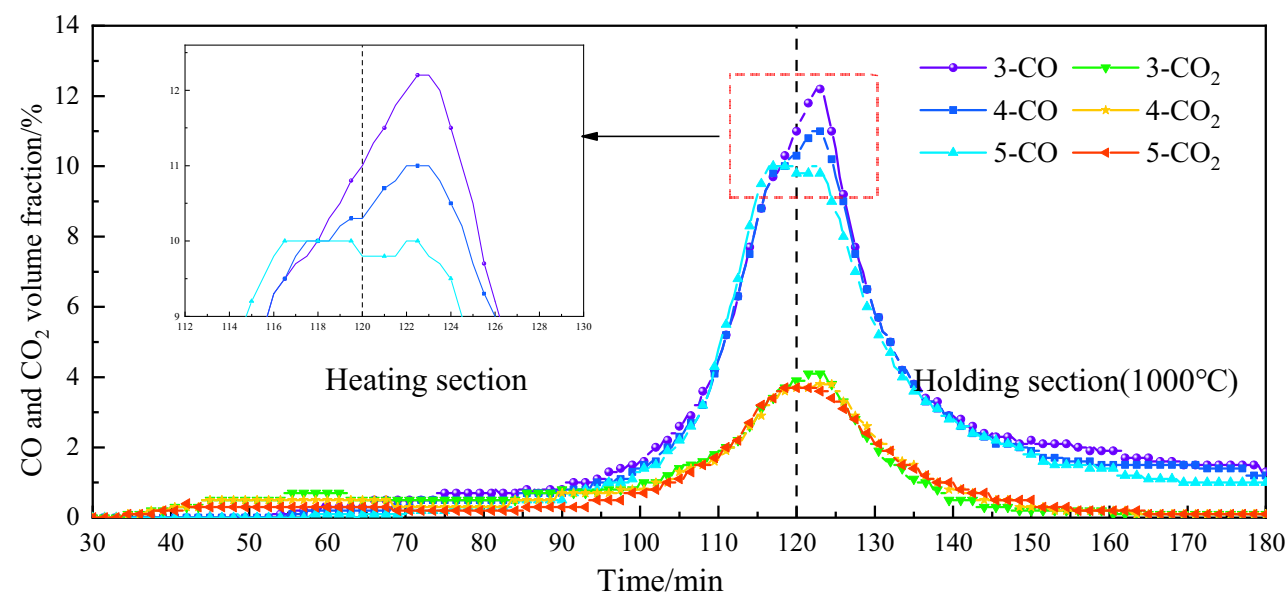

Figure 5. Changes of $\mathrm{CO}$ and $\mathrm{CO}_{2}$ volume fractions in tail gas during reduction of fully mixed pellets.

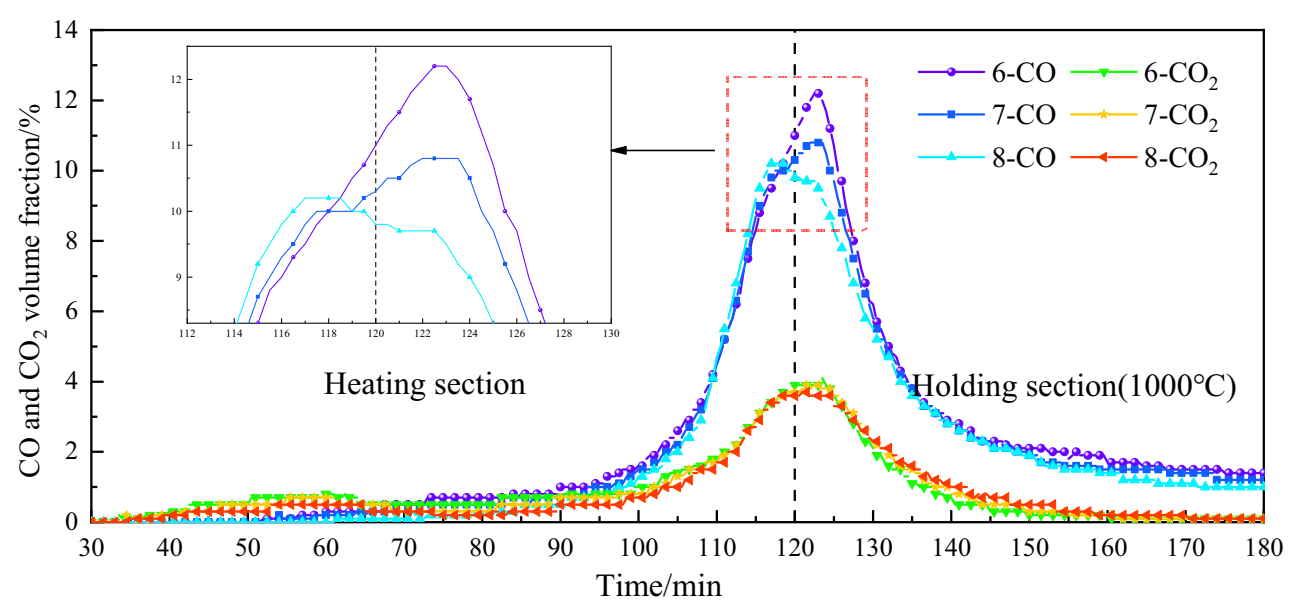

Figure 6. Changes of $\mathrm{CO}$ and $\mathrm{CO}_{2}$ volume fractions in tail gas during reduction of double-layer pellets.

2. By analyzing the composition of the tail gas, it is found that the mixed reducing agent pellets can reduce gas emissions compared with the lignite pellets. The best overall effect is the No. 6 pellet, which has a high metallization rate and low emissions. Through the analysis of the changing trend of the $\mathrm{CO}$ and $\mathrm{CO}_{2}$ volume fraction in the tail gas of the reduction process, it is found that the No. 6 pellets can maintain the $\mathrm{CO}$ volume fraction at a 
higher level, thus improving the reduction degree of vanadium-titanium magnetite.

3. By preparing pellets with a novel structure, the composite reducing agent pellets can reduce gas emissions while enhancing the reduction effect. At the same time, it can also reduce the process's dependence on specific highquality coal powder and expand the selection range of reduced coal powder. This has a positive role in promoting the development of coal-based ironmaking technology.

\section{Acknowledgements}

This research was supported by the National Key Research Development Program of China, grant number 2017YFB0603800.

\section{References}

1. A. Hasanbeigi, M. Arens, L. Price, Renew. Sust. Energ.Rev. 33, 645-658 (2014).

2. Y. Yang, M. J. Hu, Y. Li, L. Y. Wen, M. L. Hu, L. W. Hu, J Clean Prod 268, (2020).

3. J. Y. Song, Z. Y. Jiang, C. Bao, A. J. Xu, Metals 9, 15 (2019).

4. X. L. Zhou, Z. N. Du, Advanced Technologies in Manufacturing, Engineering and Materials, Pts 1-3, (Trans Tech Publications Ltd, Durnten-Zurich, 774776, 2013).

5. M. K. Sharma, V. Solanki, G. G. Roy, P. K. Sen, Ironmak. Steelmak. 40, 590-597 (2013).

6. H. L. Han, D. P. Duan, P. Yuan, Steel Res. Int. 86, 1361-1369 (2015).

7. J. J. Gao, L. K. Hong, J. Zhang, Y. H. Qi, D. L. Yan, Iron Steel Vanadium Titanium 39, 8-13 (2018).

8. J. J. Gao, X. Y. Wan, Y. H. Qi, F Wang, Journal of Iron and Steel Research 91-96 (2018).

9. B. Wang, X. Y. Ding, T. H. Ju, X. F. Zhang, G. J. Cheng, Metals 11, (2021).

10. L. Y. Shi, Y. L. Zhen, D. S. Chen, L. N. Wang, T. Qi, ISIJ Int. 58, 627-632 (2018).

11. T. Hu, X. W. Lu, C. G. Bai, G. B. Qiu, Int. J. Miner. Metall. Mater. 21, 131-137 (2014).

12. H. J.Ge, W. T. Zhou, Y. L. Guo, X. Y. Zhao, Sintering and Pelletizing, 39, 27-31+46 (2014).

13. A. A. El-Tawil, H. M. Ahmed, A. A. El-Geassy, B. Bo, in Conference of Metallurgists. (2015).

14. K. Watanabe, S. Ueda, R. Inoue, T. Ariyama, ISIJ Int. 50, 524-530 (2010).

15. P. Yuan, B. X. Shen, D. P. Duan, G. Adwek, X. Mei, F. J. Lu, Energy 141, 472-482 (2017).

16. S. Ueda, K. Watanabe, K. Yanagiya, R. Inoue, T. Ariyama, ISIJ Int. 49, 1505-1512 (2009). 